\title{
Progress in Head and Neck Cancer Immunotherapy: Can Tolerance and Immune Suppression Be Reversed?
}

\author{
Robert L. Ferris \\ Departments of Otolaryngology and Immunology, Hillman Cancer Center Research Pavilion, Pittsburgh, Pa., USA
}

\section{Key Words}

Cancer vaccines · Tumor antigens · Immunotherapy · Dendritic cells · Cytokines

\begin{abstract}
The incidence of squamous cell carcinoma of the head and neck (SCCHN) is greater than 40,000 cases per year in the United States, and approximately 500,000 cases annually worldwide. Despite significant advances in detection, ablation, and reconstruction, survival has not improved appreciably over the past few decades. Therefore, novel approaches are necessary to provide head and neck oncologists with a more effective armamentarium against this challenging disease. Cancer immunotherapy describes various approaches to expand and activate the immune system to control tumor growth in vivo. So far, immunotherapy appears to have had applicability in conjunction with other therapeutic interventions that treat residual tumor cells after therapy or to reduce the occurrence of second primary tumors. In particular, diseases such as SCCHN are attractive candidates for novel therapeutic approaches, since the standard treatments have not yet successfully controlled this disease with sufficiently high success rates. This article reviews adjuvant immunotherapeutic strategies currently in trials or under development for SCCHN patients, including vaccination or cytokine immunostimulation.
\end{abstract}

Copyright $\odot 2004$ S. Karger AG, Basel

\section{Introduction}

The incidence of squamous cell carcinoma of the head and neck (SCCHN) is greater than 40,000 cases per year in the United States, and approximately 500,000 cases annually worldwide $[1,2]$. Clinical cancer vaccine trials that have been performed for SCCHN basically follow two different approaches: utilizing tumor antigens derived from whole cells, when tumor antigens are not (and need not be) known, or targeting defined antigens, for the few specific antigens identified in SCCHN (table 1). While the former approach consists of polyvalent immunotherapy against the heterogeneous mixture of tumor antigens present in the patient's own tumor cells, monitoring of specific immune responses to the immunotherapy is problematic in this setting. However, immunotherapy using defined antigens (table 2), while limiting the spectrum of immune responses possible, has the advantage of permitting very sensitive methods for monitoring and characterization of vaccine-induced immunity, recently developed and refined for such purposes. Careful application of either approach, however, will likely help investigators to further understand the role of immunological effector cells in controlling cancer growth in vivo. After a brief background review of the molecular basis for $\mathrm{T}$ cell recognition of tumor cells, immunological effects and toxicities that have been observed in these trials will be discussed.

\begin{tabular}{ll}
\hline KARGER & ( ) 2004 S. Karger AG, Basel \\
0301-1569/04/0666-0332\$21.00/0 \\
$\begin{array}{l}\text { Fax +4161306 1234 } \\
\begin{array}{l}\text { E-Mail karger@karger.ch } \\
\text { www.karger.com }\end{array}\end{array}$ & $\begin{array}{l}\text { Accessible online at: } \\
\text { www.karger.com/orl }\end{array}$
\end{tabular}

Robert L. Ferris, MD, PhD

Departments of Otolaryngology and Immunology, Hillman Cancer Center

Research Pavilion, 5117 Centre Avenue, L1.19d

Pittsburgh, PA 15213 (USA)

Tel.+1 412623 7703, Fax +1 412623 1415, E-Mail ferrisrl@upmc.edu 
Table 1. Tumor antigens recognized by $\mathrm{T}$ cells

Antigens encoded by genes specifically expressed by tumors Antigens encoded by variant forms of normal genes that have been altered by mutation ( $\beta$-catenin, caspase 8 , mutated $\mathrm{p} 53$ )

Antigens normally expressed only at certain stages of differentiation or only by certain differentiation lineages (cancer-testis antigen) Antigens that are overexpressed by tumors (Her/2-neu, p53)

Table 2. Potential TAA in SCCHN

HPV-16/18-derived proteins (E6 and E7 viral oncoproteins [19]) MAGE 1-6 (overexpressed differentiation antigen [36])

NY-ESO-1 [37]

Epithelial cell adhesion molecule

Pemphigus vulgaris antigen [Ferris and Godfrey, unpubl. data]

\section{Tumor Antigen Processing and Presentation}

While effective antitumor immune responses likely involve many elements of the immune system and classes of biological molecules produced by tumor cells, $\mathrm{T}$ lymphocytes continue to be considered the critical immune cells involved in antitumor immunity. CD8+ cytolytic $\mathrm{T}$ lymphocytes (CTL) appear to play a key role in the effector phase of this response, and CD4+ T helper type 1 cells provide essential cytokines for induction and maintenance of this response, and for the establishment of immunologic memory. Both of these T cell subsets recognize short peptides derived from cellular proteins present in a target antigen-presenting cell (APC), which are presented in association with major histocompatibility complex (MHC) molecules on the tumor cell surface for $\mathrm{T}$ cell recognition (fig. 1).

In the class I MHC processing pathway, tumor cells degrade linear, unfolded endogenous proteins, through a large protease complex called the proteasome, into short 8- to 10-amino acid peptide fragments. These peptides are then pumped into the endoplasmic reticulum in an adenosine triphosphate-dependent fashion through the transporter associated with antigen processing complex (TAP $1 / 2$ heterodimer). A TAP $1 / 2$-independent pathway has been identified but appears to be a minor contributor. In the endoplasmic reticulum, peptides bind to appropriate MHC class I molecules based on predictable sequence motifs and bind the class I MHC light chain, $\beta_{2}$-microglobulin. These stable complexes are then transported to the cell surface through the Golgi apparatus where they are presented on the cell surface to circulating CD8+ T cells. It should be noted that tumor cells are thought to be recognized, mainly by CD8+ CTL due to the low or absent expression of class II MHC molecules on their cell surface (fig. 2).

In the class II MHC processing pathway, professional APC, such as dendritic cells and macrophages (fig. 1), take up exogenous proteins released from damaged or apoptotic tumor cells through endocytosis. These endocytic vacuoles fuse with the acidic liposomes, activating acid proteases and degrading the ingested antigens. The resulting peptides are then presented on the cell surface to CD4+ T helper cells. In this way, professional APC do have the ability to process and present proteins originally encoded by nearby cells. The act of a surrogate cell receiving, processing, and presenting intracellular material from another cell is called 'cross-presentation' or 'cross-priming' (described below). A further distinction of dendritic cells is the expression of a modified proteasome ('immunoproteasome') of altered specificity due to the incorporation of several unique, IFN- $\gamma$-inducible subunits not normally present in tumor cell proteasomes, or other nonprofessional APC.

Thus, the identification of the relevant immunogenic peptides, i.e., those processed and stably presented in association with MHC molecules at high levels on the surface of tumor cells, must be performed directly on tumor cells through in vitro studies. Critical technical progress has been made over the past 5 years enabling a bioinformatic analysis of a tumor antigen, based on the primary amino acid sequence. The purpose of such an analysis is to predict peptides capable of binding to specific MHC molecules. This predictability follows from the accumulated knowledge that certain MHC alleles bind peptides in a predictable fashion, using MHC allele-specific motifs. A particular molecule contains pockets within its peptidebinding groove, which engage certain side chains of the peptide molecule, found at specific positions called main anchor residues. These interactions determine how tightly the MHC molecule binds the peptide ligand. Certain peptides would be predicted to bind tightly if they have the appropriate primary amino acid sequence and side chains to 'fit' into the binding cleft of the MHC allele of interest. The characterization of these peptide binding motifs for HLA class I and class II types has enabled the testing of candidate peptides from known tumor antigens whose amino acid sequence has been determined. Several strategies are employed through a combination of bioinformatics and bench experimentation to confirm their immuno- 
Fig. 1. Antigen processing and presentation to CD4+ and CD8+ T lymphocytes.
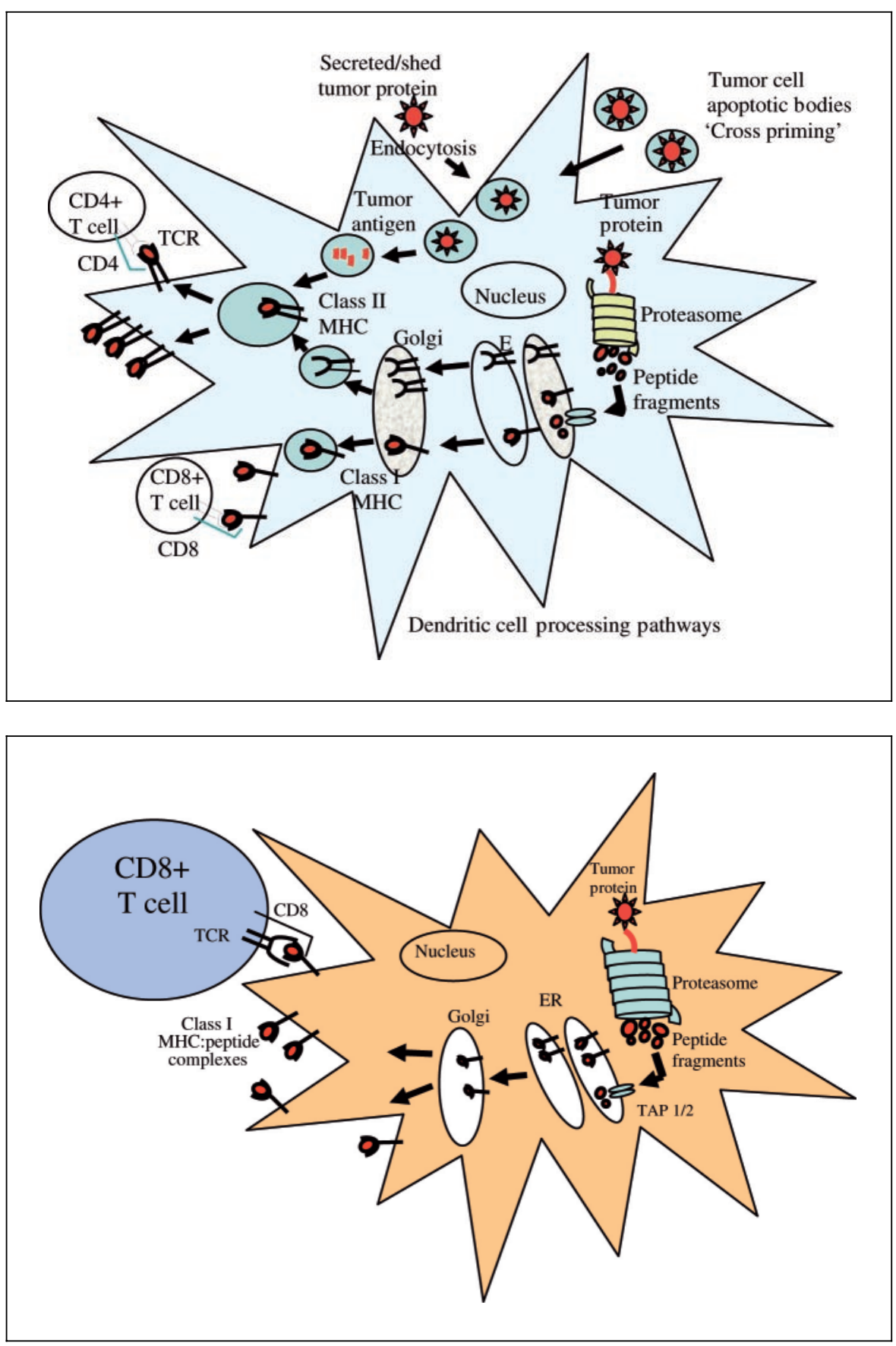

Fig. 2. Tumor antigen processing and presentation to CD8+ CTL. ER = Endoplasmic reticulum.

genicity, using in vitro binding assays and the capacity for each peptide to demonstrate $\mathrm{T}$ cell activation.

It has now been well demonstrated that SCCHN cells express both unique and shared antigens capable of being recognized by $\mathrm{T}$ cells. These tumor-associated antigens (TAA) comprise short peptide segments (8-20 amino acids in length), which may be derived from any tumor encoded protein. $\mathrm{T}$ cells recognize these TAA through their specific T cell receptor (TCR) in the context of MHC class I or class II molecules on the surface of the tumor cells. In professional APC, such as dendritic cells, two distinct pathways have been identified and characterized for the processing and presentation of $\mathrm{T}$ cell reactive TAA (fig. 1). Nonprofessional APC, however, including tumor 
cells, exclusively process and present MHC-class-I-associated peptides derived from endogenous antigens (fig. 2).

\section{Candidate Antigens for Clinical Head and Neck Cancer Immunotherapy}

TAA can be divided into the general categories outlined in table 1. As mentioned above, cancer immunotherapy relies on two separate approaches: tumor antigens and the design of SCCHN vaccines. The first holds that tumor rejection is best induced by immunizing with unique tumor antigens, based on the use of undefined tumor-derived products as vaccine. The strength of this approach is that shared, 'self' antigens, which appear to predominate as targets of tumor-specific immunity, are used without the need for specific identification of particular antigenic targets. In this way, immunotherapy can be performed using irradiated tumor cells themselves, or tumor-derived materials - such as tumor cell lysates or apoptotic tumor cell bodies - as substrates for generating a specific antitumor immune response. While irradiated tumor cells provide simplicity and avoid practical issues involved in the preparation of the vaccine, this approach relies on the tumor cell as an effective APC itself, a notion that has been clearly faulted by numerous reports involving antigen processing defects and downregulation of $\mathrm{MHC}$ by tumor cells themselves. These findings are obvious in retrospect, explaining the tumor's evasion of endogenous antitumor immunity in these patients from whom the tumor originated. While cross-presentation of these TAA might occur in this setting, a number of hurdles have been suggested to explain the failure of this approach. These include variability in the dose of tumor antigens delivered, the localization of dendritic cells to the site of tumor antigen expression, and reliance on the immunosuppressed host (patient) to take up, process and present the tumor antigens endogenously, an obvious hurdle highlighted by the inability to control the tumor solely in this way.

The TAA that have been described in SCCHN cells to date are derived from a broad spectrum of intracellular proteins (table 2). Some of these TAA are specific to an individual tumor cell. Targeting unique mutated TAA is likely to be so laborious as to be impractical in clinical practice, since each patient's TAA would have to be studied first. A second category of TAA, which appear to comprise most tumor-specific antigens, are those antigens shared among different tumors but confined to malignant cells. These may be transcriptionally reactivated genes not
Table 3. Tumor peptide antigens specifically presented by SCCHN cells

CASP-8 (unique mutation [38])

Carcinoembryonic antigen

(overexpressed differentiation antigen [39])

p53 (mutated and overexpressed with wild-type antigens [8])

expressed in normal host tissues, referred to as embryonic, developmental, or 'cancer-testis antigens'. These antigens are present only at certain stages of development as well as in the male testis organs. A related category is the tissue differentiation antigens, which are exclusively expressed by cells of origin of the tumor but not expressed in other tissues (tyrosinase in melanoma cells). The last category of TAA are those that are overexpressed, or accumulated, in tumor cells that are also present in normal tissues. It is the differential level of expression of these antigens in tumor cells providing a therapeutic window for immunotherapy strategies targeting wild-type peptide sequences. Finally, TAA from viral-associated tumors, such as Epstein-Barr virus and oncogenic human papillomavirus (HPV) subtypes, could serve as tumor-specific targets for the immune system. Tumor-specific peptides are derived from unique mutated proteins not found in normal host cells and tissues or from such overexpressed TAA, and a small number of these peptides (and their restricting human leukocyte antigen molecule) have been identified in SCCHN (table 3).

\section{Antigen-Presenting Cells}

Dendritic cells are ideally suited as APC because of their unique features, including the ability to take up an exogenous antigen, process it efficiently, and present it on the cell surface in association with MHC molecules. Furthermore, because of their strategic location at sites of potential pathogen entry and because of their ability to migrate from these primary sites into secondary lymphoid tissues for $\mathrm{T}$ cell activation, dendritic cells fulfill all criteria as the pivotal immunomodulatory cell, linking innate and adaptive immune response. Their unique features enable them to activate both helper and cytotoxic $\mathrm{T}$ cells. Dendritic cells also interact with B cells and natural killer cells and thus direct and orchestrate the magnitude and quality of the resulting immune response. Recent work 
[3-5] has even shown that dendritic cells can deliver death signals to tumor cells directly.

A critical principle of dendritic cell biology is the concept of 'immaturity' and 'maturity', indicating phenotypic and functional distinctions along this cellular spectrum. While dendritic cells are derived from the 'myeloid' (CD11c+) or 'lymphoid' (CD123+) differentiation pathways, the maturity status of the dendritic cell is critical to its function, as described below. Myeloid dendritic cells are best studied to date, but recent investigation aims to clarify whether functional or phenotypic differences exist between dendritic cells from each lineage.

Immature dendritic cells are quite adept at taking up exogenous antigens and processing these proteins into short peptide fragments for stimulation of CD8+ and CD4+ T cells. Various proinflammatory stimuli, including soluble cytokine ligands (IL-1 $\beta$, TNF- $\alpha$, IL-6, prostaglandin E) as well as other cell-based receptor interactions (CD40 ligand) lead to the conversion of these dendritic cells to a different phenotype, termed mature dendritic cells. These maturation signals may lead to the upregulation of various different cell surface costimulatory molecules; however, they are often described as if they were identical in some publications. For instance, the ability to take up apoptotic tumor cell bodies or tumor lysate protein mixtures is significantly improved by exposure to a cocktail of proinflammatory cytokines and ligation of the CD40 receptor. In addition, simply the process of 'crosspriming' or taking up apoptotic bodies or cell lysate protein mixtures triggers a version of the maturation program. After 12-24 h, this program leads to the decreased ability to take up exogenous material and an increase in the processing, antigen presentation, and costimulatory functions of the, now mature, dendritic cells. Components of the antigen processing machinery [including the proteasomal subunits low-molecular-weight protein (LMP)-2, LMP-7 and LMP-10] lead to altered specificity and increased efficiency of these reactions. As noted above, a major subset of dendritic cells is from the 'lymphoid' differentiation origin (expressing the CD123 molecule). These cells appear to be different from 'myeloid' dendritic cells, notably in their production of large amounts of INF- $\alpha$. The exact role of these CD123+ lymphoid dendritic cells is unclear due to the focus of recent investigation on the 'myeloid' (CD11c+) subsets. New insights will likely emerge as these different dendritic cell subsets are understood more fully in terms of their differentiation history and maturation phenotypes, enabling a better understanding of their endogenous biological role and immunotherapeutic value.

\section{Peptide-Based Immunotherapy}

At present, several peptide-based vaccines are undergoing clinical evaluation or are in development. One of the challenges of peptide-based vaccines is the identification of appropriate $\mathrm{MHC}$ alleles that will bind with the synthetic peptide and, thus, stimulate an immune response. Thus, human leukocyte antigen (HLA) molecules may restrict the candidacy for this approach. Though they are extremely polymorphic within the general population and have particular ethnic variations, certain supertype or overlapping peptide repertoires have been identified and can be used to group particular HLA alleles into broad families [6]. Now that over 1,000 patients have received cancer vaccines, most of these trials indicate that peptide vaccination has few toxicities associated with its administration, but discordance exists between in vitro and clinical responses. However, this represents an evolving field and, thus, firm conclusions concerning the efficacy of peptide-based vaccines for cancer immunotherapy are elusive. Improvements in peptide vaccination, such as the addition of various adjuvants, the utilization of peptidepulsed dendritic cells, multipeptide vaccinations, or the addition of helper peptides are encouraging and serve as important guides for future studies.

\section{p53 Molecules and Multivalent Peptide-Based Vaccines}

A number of investigators are also taking advantage of the common overexpression of p53 molecules in many different cancers to develop multivalent peptide-based vaccines utilizing dendritic cells for optimal immunestimulating effect [7, 8]. Several studies [7-9] have revealed that a subset of T cells from patients with SCCHN can recognize and lyse SCCHN cell lines overexpressing the $\mathrm{p} 53$ protein - a prerequisite for effective immunotherapy for such patients. Studies [10,11] also suggest that nonresponsiveness of certain wild-type p53-specific $T$ cells can be reversed by exposure to dendritic cells loaded with an optimized peptide modified at one amino acid position, with improved binding to its cognate TCR.

Work in preclinical models by DeLeo's group $[12,13]$ demonstrated efficacy in tumor rejection in mice immunized with dendritic cells pulsed with wild-type p53 peptide. These data have led to the development of a single epitope wild-type p53-specific vaccine (table 2) for application in SCCHN patients, and patients with colon and ovarian carcinoma, at the National Cancer Institute 
(NCI) [14]. Entry criteria included detectable staining for tumor $\mathrm{p} 53$, indicative of $\mathrm{p} 53$ 'overexpression'.

Because SCCHN comprises patients whose tumors are associated with infection by HPV oncogenic types, which cause degradation of $\mathrm{p} 53$, overexpression of $\mathrm{p} 53$ may not be seen in up to $30 \%$ of these patients [40]. Therefore, selection criteria for wild-type $\mathrm{p} 53$-based vaccination for SCCHN must not exclude these individuals, based on the lack of p53 overexpression detected in their tumors, as was done in the NCI trials. A multi-epitope wild-type p53based vaccine using peptide-loaded dendritic cells (Ferris, principal investigator) is currently under way at the University of Pittsburgh, funded by the NCI Head and Neck Specialized Program of Research Excellence mechanism. Accrual for the phase I/II safety and immunogenicity trial will begin late 2004, and will include early-stage SCCHN patients, in whom immunosuppression is likely to be reduced. Prospects are good that low toxicities will be seen and that immunologic responses will be achieved. In addition to detailed immunologic monitoring of vaccineinduced responses and evidence for tumor immune escape, clinical outcome, although not a primary measure of this trial, will be tracked.

\section{Adoptive Transfer}

Adoptive immunotherapy describes the passive transfer of immunologically active cells into a patient to mediate tumor regression, either directly or indirectly. These tumor-reactive cells are generated by ex vivo expansion and activation through a variety of means. Ligation of the TCR using monoclonal antibodies (such as anti-CD3), often with the addition of anticostimulatory molecule activation (using anti-CD28 monoclonal antibodies), appears to be optimal.

Clinical trials of adoptive $\mathrm{T}$ cell transfer have been conducted in melanoma, renal cell carcinoma, and lung and breast cancer, and only sparingly in SCCHN. Clinical response has not been seen in preliminary studies [15] of 6 patients with SCCHN in whom T lymphocytes expanded ex vivo were infused - despite the ability of some of the adoptively transferred lymphocytes to recognize and secrete cytokines in response to autologous tumor cells. Anti-CD3-activated vaccine-primed lymph node (VPLN) cells secreted IFN- $\gamma$ and GM-CSF in response to autologous tumor cells but not to allogeneic tumor cells in 4 of 5 patients analyzed. Both CD4+ and CD8+ tumor-reactive cells were present in the VPLN. There were no significant tumor responses after transfer of the anti-CD3-activated
VPLN. In separate experiments, costimulation of VPLN cells with anti-CD3 and anti-CD28 monoclonal antibodies resulted in enhanced cytokine secretion to autologous tumor compared with anti-CD3 activation alone. In conclusion, both $\mathrm{CD} 4+$ and $\mathrm{CD} 8+$ responses can be induced to squamous cell carcinoma by autologous tumor vaccination. However, additional approaches need to be identified to enhance the therapeutic efficacy of this approach.

\section{Transfer of Gene-Modified APC}

Although immunization using autologous irradiated tumor cells is appealing because of its simplicity and its avoidance of challenges involved in ex vivo propagation of tumor or immune cells, the tumor cell itself generally cannot process and present adequate levels of TAA to result in effective tumor-specific immunization. Investigations in animal models using the transfection of surrogate APC with tumor-derived DNA or whole protein from tumor lysates or apoptotic tumor cells have been performed to circumvent these hurdles while leveraging the enormous diversity of gene expression and antigenic disparity between normal and malignant cells [16].

Cohen et al. [16, 18] have transfected DNA from brain or breast cancer cells into a mouse fibroblast cell line expressing high levels of MHC molecules along with B7.1, a critical costimulatory molecule. The acceptor cell in such a 'cross-priming' strategy may be either a professional APC, such as a dendritic cell, or as in a recently initiated trial [17], an allogeneic master cell transfected with high levels of the IL-2 gene, the secretion of which enhances $T$ cell stimulation [18] and combines local inflammatory 'danger' signals with tumor antigen expression. Preclinical work indicates promising success at constructing such a master cell for patient application and FDA approval is currently being sought. While dendritic cells provide high levels of MHC and costimulatory molecule expression, as well as the theoretical secretion of critical cytokines for $\mathrm{T}$ cell growth and activation, variations in their isolation and maturation make comparisons between dendritic cell-based vaccines using tumor protein or APC-derived antigen sources difficult. However, according to the experience reported by Cohen's group [18], the generalized alloimmune response inherent in this vaccine may reverse tolerance to tumor antigens by presenting them as classical 'danger' signals: foreign MHC molecules. Thus, activation of innate immune responses in the context of patient-specific tumor gene expression appears synergistically beneficial. 
Table 4. SCCHN vaccine trials (ongoing)

\begin{tabular}{llll}
\hline Sponsor & Trial & Sites & Indication \\
\hline $\begin{array}{l}\text { Cincinnati } \\
\text { (multicenter) }\end{array}$ & $\begin{array}{l}\text { Allovectin-7 (HLA B7) immunotherapy } \\
\text { (phase II) }\end{array}$ & OC/OP & resectable [23] \\
\hline NIH & $\begin{array}{l}\text { recombinant Fowlpox-Tricom vaccine } \\
\text { (phase I) }\end{array}$ & $\begin{array}{l}\text { all head and neck } \\
\text { sites }\end{array}$ & unresectable stage IV \\
\hline NCI & HPV-16 E6 E7 peptide vaccine (phase II) & all head and neck sites & stage II/IV, recurrent [19] \\
\hline UPMC & $\begin{array}{l}\text { apoptotic tumor cells/dendritic cells } \\
\text { (autologous) }\end{array}$ & head and neck sites & $\begin{array}{l}\text { resectable with cervical } \\
\text { metastasis [17] }\end{array}$ \\
\hline UPMC & $\begin{array}{l}\text { wild-type p53 multipeptide-loaded } \\
\text { dendritic cells }\end{array}$ & head and neck sites & $\begin{array}{l}\text { no evidence of disease after } \\
\text { surgery and/or chemo/radio- } \\
\text { therapy all stages of disease } \\
\text { [8, 40] }\end{array}$ \\
\hline
\end{tabular}

$\mathrm{NIH}=$ National Institutes of Health; UPMC = University of Pittsburgh Medical Center; OC/OP = Oral cavity/ Oropharynx.

\section{Nucleic Acid Vaccines}

\section{DNA/RNA-Based Tumor Antigen Delivery}

Several experimental animal studies $[19,20]$ have demonstrated that plasmid-based DNA vaccines can induce immune responses to HPV-16 E7 protein in humans. The approach is being applied in a clinical trial at Johns Hopkins (Gillison, principal investigator), for HPV-16+ SCCHN patients in the adjuvant setting, for patients with no evidence of disease. Accrual is expected to begin in the near future, specifically targeted to oropharyngeal squamous cell carcinoma patients with evidence of HPV infection in their tumor.

Although nucleic acid vaccines do not appear to induce as vigorous an immune response as live viral vaccine vectors, they have several advantages: (1) generation of large quantities of nucleic acid reagents for the tumor-associated gene of interest is easily accomplished; (2) DNA-based plasmid vectors remain stable in a wide range of conditions over great lengths of time; (3) DNA-based plasmid vectors can be delivered with little risk to individuals who are immunosuppressed; (4) multiple injections can be given to induce an immune response, and (5) the cellular machinery needed to generate tumor antigens and other vaccine proteins are provided by the host and not required to be incorporated into the vaccine itself.

DNA vaccines are administered using several methods. Intramuscular injection is the most common. Another method is the 'gene gun' technique, in which tiny parti- cles coated with the DNA plasmid are incubated intradermally, after which the DNA is taken up and expressed by Langerhans cells. It should be noted that this technique is a proof of principle that has not received FDA approval for human use. Other approaches of gene delivery, such as adenovirus wild-type p53 [21] or bacterial (recombinant Listeria monocytogene vector [22]), may be applicable to this population of patients.

Another interesting DNA-based immunotherapy is the use of allogeneic HLA B7 gene transfer, known as Allovectin-7, currently in use for SCCHN. This approach consists of an allo-MHC class I gene, HLA B7, cotransfected into tumors with the $\beta_{2}$-microglobulin, for the purpose of generating a strong 'danger' signal leading to inflammatory antitumor responses. Results of phase I/II trials are promising $[23,24]$. In a study of 60 patients with advanced refractory SCCHN, a partial response was achieved in 6 $(10 \%)$ patients and stable disease was seen in $14(23 \%)$ patients following 1 cycle of treatment. Trials of Allovectin-7 as an adjuvant therapy in patients with earlier-stage SCCHN are being planned.

\section{Cytokine-Based Immunotherapy}

In cytokine-based immunotherapy direct intratumoral or locoregional proinflammatory cytokine delivery is performed. Alternatively, tumor cells are engineered to secrete stimulatory cytokines (IL-2, GM-CSF) or to directly express relevant costimulatory molecules (B7.1) needed for T cell activation. The latter method exploits the TAA pro- 
vided by the whole tumor cell, attempting to reverse the host tolerance in the likely immunosuppressive tumor site.

Extensive preclinical studies [25-27] demonstrated that the greatest systemic immune enhancement in mouse tumor models of SCCHN was achieved through the use of IL-2 and IL-12, or GM-CSF. A similar effect has recently been seen in an immunotherapy trial for the treatment of human renal cell or breast carcinoma [28, 29], indicating that their application for SCCHN is a promising approach. The effectiveness of GM-CSF may be in its ability to locally recruit and activate dendritic cell precursors at the site of the tumor cell vaccine. Studies directed at other types of tumors are ongoing. No significant toxicity has been observed. Tumor-reactive $\mathrm{T}$ cells were isolated and propagated ex vivo demonstrating the capacity for immunologic responses to be monitored in the course of vaccination.

A clinical report by De Stefani et al. [30] of ongoing experience with cervical perilymphatically injected IL-2 in patients with SCCHN demonstrated a statistically significant survival advantage in patients with resectable SCCHN (T2-T4, N0-N3, M0 squamous cancers of the oral cavity and oropharynx). The regimen included preoperative and postoperative low-dose IL-2 injections (5,000 U per day) delivered as part of standard surgery with or without radiotherapy. In all, 202 patients completed the study. No significant complications related to recombinant IL-2 were encountered. Significantly lengthened disease-free survival and longer overall survival was consistently seen in patients receiving recombinant IL-2 whether or not worrisome features such as perineural invasion or capsular rupture from the cervical nodes were observed. However, vascular invasion was associated with decreased efficacy of recombinant IL-2, with 5-year disease-free survival rates statistically similar in the recombinant IL-2 and control groups. The risk of micrometastasis may be increased in patients with vascular invasive tumors, abrogating the locoregional benefit of cervical perilymphatic recombinant IL-2 injections. Other investigators [31] have performed intratumoral administration of IL-2 encoding DNA sequences and found little toxicities. Further immunological monitoring is being conducted. A number of groups [32-34] advocate the locoregional administration of a mixture of selected cytokines to broaden the immune response. Often clinical and pathologic effects are seen, consistent with inflammatory infiltrates, but detailed immunological monitoring for tumorspecific activity has not been published.

Restoration of critical inflammatory signals may recruit immune cells into the tumor site. Other forms of immune escape from recognition must be reversed. A trial currently in development at the University of Pittsburgh involves intratumoral (locoregional) administration of recombinant human IFN- $\gamma$. This phase I trial will enable immunologic monitoring of HLA class I expression (restoration) and antigen processing machinery (fig. 1), which has been repeatedly shown to be downregulated in patients with SCCHN other tumors. Recent data [35] suggest that clinical outcomes of SCCHN patients might correlate with HLA expression levels. Downregulation of components of the antigen processing machinery and HLA molecules were related to survival, indicating the need to understand the mechanisms of immune escape and to test strategies for its reversal.

\section{Conclusion}

A number of novel approaches are in development to improve therapeutic options for patients with SCCHN and other forms of cancer. The promise of immunotherapy lies in its specificity, potential potency, and versatility. So far, the use in the adjuvant setting to complement existing therapies has been the most common application of immunotherapy. These vaccine recipients are at highest risk for recurrence of primary disease, but they are also those least likely to demonstrate immunologic responses to vaccination. Expansion of phase I and II trials to earlystage SCCHN patients would increase the likelihood of detecting promising responses. These patients have lower tumor burden, better nutrition and decreased time of tumor-associated immune dysregulation.

In addition to adjuvant treatment, immunotherapy might have important clinical utility in reducing second primary tumors of the upper aerodigestive tract in a chemopreventive fashion, since this is a major determinant of long-term survival in SCCHN patients. The inexorable frequency to these tumors is often difficult to detect with routine follow-up intervals of months or years after first tumor 'cure.'. Clinical application in the coming years will likely demonstrate the most appropriate role of immunotherapy in conjunction with other adjuvant therapies utilized in head and neck oncologic care.

\section{Acknowledgements}

I would like to thank the Stout Family Fund for Head and Neck Cancer Research, the FAMRI Young Clinical Scientist Award, and the Eye and Ear Foundation of Pittsburgh for support. Mr. Chance Newman was very helpful in the production of the manuscript. 


\section{References}

1 Greenlee RT, Hill-Harmon MB, Murray T, 15 Chang AE, Li Q, Jiang G, Teknos TN, Chepeha Thun M: Cancer statistics, 2001. CA Cancer J Clin 2001;51:15-36.

2 American Cancer Society: Cancer Facts and Figures. Atlanta, American Cancer Society, 1997.

-3 Lu G, Janjic BM, Janjic J, Whiteside TL, Storkus WJ, Vujanovic NL: Innate direct anticancer effector function of human immature dendritic cells. 2. Role of TNF, lymphotoxinalpha(1)beta(2), Fas ligand, and TNF-related apoptosis-inducing ligand. J Immunol, 2002; 168:1831-1839.

4 Janjic BM, Lu G, Pimenov A, Whiteside TL, Storkus WJ, Vujanovic NL: Innate direct anticancer effector function of human immature dendritic cells. 1. Involvement of an apoptosisinducing pathway. J Immunol 2002;168:18231830.

$>5$ Vujanovic NL: Role of TNF family ligands in antitumor activity of natural killer cells. In Rev Immunol 2001;20:415-437.

6 Brinkman JA, Fausch SC, Weber JS, Kast WM Peptide-based vaccines for cancer immunotherapy. Expert Opin Biol Ther 2004;4:181198.

7 Theobald M, Biggs J, Dittmer D, Levine AJ, Sherman LA: Targeting p53 as a general tumor antigen. Proc Natl Acad Sci USA 1995;92: 11993-11997.

8 DeLeo AB: p53-based immunotherapy of cancer. Crit Rev Immunol 1998;18:29-35.

9 Chikamatsu K, Nakano K, Storkus WJ, Appella E, Lotze MT, Whiteside TL, DeLeo AB: Generation of anti-p53 cytotoxic T lymphocytes from human peripheral blood using autologous dendritic cells. Clin Cancer Res 1999;5: 1281-1288.

10 Hoffmann TK, Loftus DJ, Nakano K, Maeurer MJ, Chikamatsu K, Appella E, Whiteside TL, DeLeo AB: The ability of variant peptides to reverse the nonresponsiveness of $\mathrm{T}$ lymphocytes to the wild-type sequence p53(264-272) epitope. J Immunol 2002;168:1338-1347.

$\checkmark 11$ Petersen TR, Buus S, Brunak S, Nissen MH, Sherman LA, Claesson MH: Identification and design of p53-derived HLA-A2-binding peptides with increased CTL immunogenicity. Scand J Immunol 2001;53:357-364.

12 Mayordomo JI, Zorina T, Storkus WJ, Zitvogel L, Celluzzi C, Falo LD, Melief CJ, Ildstad ST, Kast WM, Deleo AB, et al: Bone marrowderived dendritic cells pulsed with synthetic tumour peptides elicit protective and therapeutic antitumour immunity. Nat Med 1995; 1297-1302.

-13 Mayordomo JI, Loftus DJ, Sakamoto H, De Cesare CM, Appasamy, PM, Lotze MT, Storkus WJ, Appella E, DeLeo AB: Therapy of murine tumors with p53 wild-type and mutant sequence peptide-based vaccines. J Exp Med 1996;183:1357-1365.

14 Herrin V, Achtar M, Monahan B, Bernstein S, Brent-Steele T, Whiteside T, Wieckowski E, Berzofsky J, Khleif SN: Wild-type p53 peptide vaccine can generate a specific immune response in low burden ovarian adenocarcinoma. Abstract No 678. ASCO Meet, Bethesda, 2003.
$\mathrm{DB}$, Bradford $\mathrm{CR}$ : Generation of vaccineprimed lymphocytes for the treatment of head and neck cancer. Head Neck 2003;25:198209

16 Cohen EP: Cancer therapy with DNA-based vaccines. Immunol Lett 2000;74:59-65.

17 Whiteside TL, Gambotto A, Albers A, Stanson J, Cohen EP: Human tumor-derived genomic DNA transduced into a recipient cell induces tumor-specific immune responses ex vivo. Proc Natl Acad Sci USA 2002;99:9415-9420.

18 Glick RP, Lichtor T, Panchal R, Mahendra A, Cohen EP: Treatment with allogeneic interleukin-2 secreting fibroblasts protects against the development of malignant brain tumors. J Neurooncol 2003;64:139-146.

19 Devaraj K, Gillison ML, Wu TC: Development of HPV vaccines for HPV-associated head and neck squamous cell carcinoma. Crit Rev Oral Biol Med 2003;14:345-362.

20 Kim JW, Hung CF, Juang J, He L, Kim TW, Armstrong DK, Pai SI, Chen PJ, Lin CT, Boyd DA, Wu TC: Comparison of HPV DNA vaccines employing intracellular targeting strategies. Gene Ther 2004;11:1011-1018.

21 Clayman GL, el-Naggar AK, Lippman SM, Henderson YC, Frederick M, Merritt JA, Zumstein LA, Timmons TM, Liu TJ, Ginsberg L, Roth JA, Hong WK, Bruso P, Goepfert H: Adenovirus-mediated $\mathrm{p} 53$ gene transfer in patients with advanced recurrent head and neck squamous cell carcinoma. J Clin Oncol 1998;16: 2221-2232.

22 Sewell DA, Douven D, Pan ZK, Rodriguez A, Paterson Y: Regression of HPV-positive tumors treated with a new Listeria monocytogenes vaccine. Arch Otolaryngol Head Neck Surg 2004;130:92-97.

23 Gleich LL: Gene therapy for head and neck cancer. Laryngoscope 2000;110:708-726.

24 Gleich LL, Li YQ, Li S, Gluckman JL, Stambrook PJ: Alloantigen gene therapy for head and neck cancer: Evaluation of animal models. Head Neck 2003;25:274-279.

25 Li D, Jiang W, Bishop JS, Ralston R, O’Malley BW Jr: Combination surgery and nonviral interleukin 2 gene therapy for head and neck cancer. Clin Cancer Res 1999;5:1551-1556.

26 Li D, Zeiders JW, Liu S, Guo M, Xu Y, Bishop JS, O'Malley BW Jr: Combination nonviral cytokine gene therapy for head and neck cancer. Laryngoscope 2001;111:815-820.

27 O’Malley BW, Cope KA, Chen SH, Li D, Schwarta MR, Woo SL: Combination gene therapy for oral cancer in a murine model. Cancer Res 1996;56:1737-1741.

28 Emens LA, Armstrong D, Biedrzycki B, Davidson N, Davis-Sproul J, Fetting J, Jaffee E, Onners B, Piantadosi S, Reilly RT, Stearns V, Tartakovsky I, Visvanathan K, Wolff A: A phase I vaccine safety and chemotherapy dosefinding trial of an allogeneic GM-CSF-secreting breast cancer vaccine given in a specifically timed sequence with immunomodulatory doses of cyclophosphamide and doxorubicin. Hum Gene Ther 2004;15:313-337.
29 Armstrong TD, Jaffee EM: Cytokine modified tumor vaccines. Surg Oncol Clin N Am 2002; 11:681-696.

30 De Stefani AFG, Ragona R, Cavallo G, Bussi M, Usai A, Badellino F, Cortesina G: Improved survival with perilymphatic interleukin 2 in patients with resectable squamous cell carcinoma of the oral cavity and oropharynx. Cancer 2002;95:90-97.

31 Wollenberg B, Kastenbauer Mundl H, Schaumberg J, Mayer A, Andratschke M, Lang S, Pauli C, Zeidler R, Ihrler S, Lohrs Naujoks, K, Rollston R: Gene therapy - Phase I trial for primary untreated head and neck squamous cell cancer (HNSCC) UICC stage II-IV with a single intratumoral injection of hIL-2 plasmids formulated in DOTMA/Chol. Hum Gene Ther 1999;10:141-147.

32 Hadden JW: The immunopharmacology of head and neck cancer: An update. Int J Immunopharmacol 1997;19:629-644.

33 Shibuya TY, Kim S, Nguyen K, Parikh P, Wadhwa A, Brockardt C, Do J: Covalent linking of proteins and cytokines to suture: Enhancing the immune response of head and neck cancer patients. Laryngoscope 2003;113:18701884

34 Feinmesser R, Hardy B, Sadov R, Shwartz A Chretien P, Feinmesser M: Report of a clinical trial in 12 patients with head and neck cancer treated intratumorally and peritumorally with multikine. Arch Otolaryngol Head Neck Surg 2003; 129:874-881.

35 Ogino T, Bandoh N, Hayashi T, Miyokawa N, Harabuchi Y, Ferrone S: Association of tapasin and HLA class I antigen down-regulation in primary maxillary sinus squamous cell carcinoma lesions with reduced survival of patients. Clin Cancer Res 2003;9:4043-4051.

36 Eura M, Ogi K, Chikamatsu K, Lee KD, Nakano K, Masuyama K, Itoh K, Ishikawa T: Expression of the MAGE gene family in human head-and-neck squamous-cell carcinomas. Int J Cancer 1995;64:304-308.

37 Kienstra MA, Neel HB, Strome SE, Roche P: Identification of NY-ESO-1, MAGE-1, and MAGE-3 in head and neck squamous cell carcinoma. Head Neck 2003;25:457-463.

38 Mandruzzato S, Brasseur F, Andry G, Boon T, van der Bruggen P: A CASP-8 mutation recognized by cytolytic $\mathrm{T}$ lymphocytes on a human head and neck carcinoma. J Exp Med 1997; 186:785-793.

39 Kass ES, Greiner JW, Kantor JA, Tsang KY, Guadagni F, Chen Z, Clark B, De Pascalis R, Schlom J, Van Waes C: Carcinoembryonic antigen as a target for specific antitumor immunotherapy of head and neck cancer. Cancer Res 2002;62:5049-5057.

40 Sirianni NM, Ha PK, Oelke M, Califano J, Gooding W, Westra W, Whiteside TL, Koch WM, Schneck JP, DeLeo A, Ferris RL: Effect of human papillomavirus-16 infection on $\mathrm{CD} 8+\mathrm{T}$ cell recognition of a wild type sequence p53 $264-272$ peptide in head and neck cancer patients. Clin Can Res 2004;10:6929_ 6937 